\title{
As sementes geneticamente modificadas e o direito ao desenvolvimento
}

\section{The genetically modified seeds and the right to development}

\author{
Milena Barbosa de Melo \\ Doutoranda em Direito Internacional pela Universidade de Coimbra. Professora Universitária da \\ Universidade Estadual da Paraíba (UEPB) e da Universidade de Ciências Sociais e Aplicadas - \\ UNIFACISA. Consultora e pesquisadora jurídica (www.milenamelo.com) \\ E-mail:milena@milenamelo.com / milenabarbosa@gmail.com
}

\begin{abstract}
Resumo: O presente artigo apresenta como objeto de investigação a ligação entre os direitos da propriedade intelectual no contexto dos organismos geneticamente modificados (OGM'S). Objetivou-se, especificamente, responder inquietações acerca dos danos reais para os consumidores, bem como o lucro para as empresas multinacionais, sem desconsiderar, ainda, os efetivos danos ao meio ambiente e à saúde. Utilizou metodologia pautada em pesquisa bibliográfica e documental a partir do método hermenêutico fazendo uso da interpretação judicial-histórica. Conclui pela relevância da temática para efetivação do direito ao desenvolvimento, bem como pela urgência de uma regulamentação da biossegurança, de forma a permitir melhor sustentação aos OGM's.
\end{abstract}

Palavras-Chave: Propriedade Intelectual; Organismos Geneticamente Modificados; Direito ao Desenvolvimento; Biossegurança.

\begin{abstract}
This article presents as it's research object the link between intellectual property rights and genetically modified organisms (GMOs). It aimed to specifically answer concerns about the real harm to consumers and profits for multinational companies, including also the actual damage to the environment and health. Used methodology guided by bibliographical and documentary research from the hermeneutic method making use of the legal-historical interpretation. Concludes the relevance of the theme to right to development realization and the urgent regulation of biosafety, in order to enable better support to GMOs.
\end{abstract}

Keywords: Intellectual Property; Genetically modified organisms; Righ tto Development; Biosecurity. 


\section{Introdução}

O sistema agrícola mundial modificou-se com o tempo, em virtude das adversidades que surgiram nas várias regiões do mundo, nomeadamente, mudanças climáticas (seca e chuvas exageradas), crise energética, aumento dos custos da produção agrícola, acarretando, portanto, um aumento significativo no preço dos alimentos e, consequentemente, interferindo diretamente na rotina da população.

Nessa perspectiva, o presente artigo tem como objeto o estudo das questões sobre direitos de propriedade intelectual, no contexto das necessidades apresentadas pela população e ainda, a importância das questões que envolvem tais direitos e a grande influência identificada com as questões agrícolas, nomeadamente, nos organismos geneticamente modificados.

Além da mudança de foco, parte significativa das pesquisas sobre biotecnologia agrícola e quase todas as atividades de comercialização estão, na atualidade, sendo realizadas por empresas privadas transnacionais. A biotecnologia aplicada aos organismos e as sinergias entre esses e os insumos químicos provocaram uma profunda mudança na estrutura do mercado de sementes em nível global.

Nesse mesmo contexto, tornou-se possível observar o fortalecimento dos direitos de propriedade intelectual a partir do advento de convenções internacionais, que se tornou de extrema importância nas atividades desempenhadas pelas empresas transnacionais do setor agrícola.

A partir do fortalecimento dos sistemas jurídicos nacionais, no que tange aos direitos de propriedade intelectual, o mercado agrícola passou a ser analisado de uma maneira diferente, pois a variável das patentes para plantas e, ainda, de organismos geneticamente modificados passou a ser considerada, gerando, portanto, o surgimento da necessidade do pagamento dos royalties quando do uso dos organismos, já que haverá, portanto, a garantia da propriedade dos genes para as empresas transnacionais. Pelas razões expostas, justifica-se a relevância do artigo ora apresentado.

Várias discussões surgem em relação à temática proposta, especialmente quanto ao uso dos organismos geneticamente modificados, mas, o presente estudo será norteado pela seguinte pergunta problema: o uso das sementes geneticamente modificadas afetará o direito à saúde e, consequentemente, o direito ao desenvolvimento?

Revista Brasileira de Políticas Públicas e Internacionais, v.2, n.2, Dezembro/2017, pp. 03-24. 
Para responder a pergunta, ter-se-á como objetivo geral analisar se o uso dos organismos geneticamente modificados afetará a efetivação do direito a saúde e, em consequência do direito ao desenvolvimento. No intuito de alcançar as diretrizes estabelecidas anteriormente, buscar-se-á vencer as seguintes etapas: identificar se o sistema da modificação genética das sementes afeta o direito à saúde; enquadrar o direito à saúde como elemento fundamental para o direito ao desenvolvimento e analisar se o direito ao desenvolvimento é afetado a partir da entrada de sementes geneticamente modificadas no mercado de consumo.

A discussão proposta encontra-se localizada no campo das Ciências Sociais Aplicadas, especificamente no espaço da Propriedade Intelectual e encontra respaldo teórico na interlocução entre o Direito e outros territórios do conhecimento que destaquem a importância do diálogo no campo científico com pertinência à Ciência Jurídica e demais territórios do conhecimento no âmbito histórico-social. No concernente à relevância teórico-acadêmica, o trabalho procura reestabelecer novos diálogos de forma a possibilitar respostas aos novos problemas advindos do tecido social e que estão hoje a questionar o saber jurídico.

Por fim, este trabalho tem como um de seus alicerces o diálogo mediado pela Propriedade Intelectual, equilibrado como esteio à sustentabilidade, bem como o papel dos atores para a consecução do desenvolvimento. Percebe-se, assim, que o atendimento a estes preceitos constitucionais resgata a cidadania, de forma mediata. O caminho metodológico traçado consistiu em pesquisa bibliográfica e documental como espaço à construção de uma análise a partir do método hermenêutico fazendo uso da interpretação judicial-histórica.

\section{O Sistema de Propriedade Intelectual e a sua Relação com o Setor Agrícola}

As mudanças no cenário econômico, político regional e mundial, bem como o advento de novas tecnologias, especialmente biotecnologias, provocaram uma verdadeira revolução nos sistemas de propriedade intelectual que se conformaram ao longo do século XX em um grande número de tratados e acordos internacionais e foram consolidados no âmbito das negociações da Rodada do Uruguai do GATT (General Agreement on Tariffs and Trade) que deu origem à OMC (Organização Mundial do Comércio).

Revista Brasileira de Políticas Públicas e Internacionais, v.2, n.2, Dezembro/2017, pp. 03-24. 
Assim, apesar da insuficiência da disciplina dos conflitos, a legislação procura estabelecer limites. Em 1970, foi criada a Organização Mundial da Propriedade Intelectual - OMPI, com o objetivo de proteger as obras intelectuais humanas, abrangendo as áreas da ciência e da tecnologia, bem como fomentar o seu uso.

Em sequência, surgiu a Convenção de Paris sobre a Propriedade Intelectual. Esse diploma internacional disciplina a propriedade industrial, abrangendo patentes, marcas, desenhos e modelos industriais, nomes comerciais e a repressão contra a concorrência desleal, estipulando que "cada Estado contratante terá que conceder aos nacionais dos demais Estados contratantes a mesma proteção que aos seus próprios nacionais.” (MAGALHÃES, p. 149, 2011)

Ainda mais, com forte conexão com a OMPI, a União Internacional para Proteção de Obtenções Vegetais - UPOV é considerada como um sistema sui generis de propriedade intelectual e define o direito do obtentor, mediante título especial de patente, quando a pessoa cria ou descobre uma variedade vegetal. A presente convenção disciplina os requisitos para solicitação da patente, prazo para a sua existência bem como tutela os direitos do obtentor da patente.

Em sequência, com o intenso desenvolvimento industrial e a expansão do comércio nos países desenvolvidos, vislumbrou-se a necessidade de proteger o meio ambiente em sua integralidade. Assim, a Convenção sobre a Diversidade Biológica - CBD surgiu nos anos 60, tendo a sua assinatura e ratificação no Brasil somente nos anos 90.

Nesse sentido, verifica-se que os países em desenvolvimento acabam por enfrentar determinados obstáculos no que diz respeito à efetivação do direito ao desenvolvimento, pois quando se trata de engenharia genética, as dificuldades vão surgindo, já que a sociedade enfrentará, prioritariamente, problemas sociais, nomeadamente, a falta de alimentos, a qualidade dos alimentos, a efetivação do direito à saúde.

O sistema jurídico internacional concede a liberdade para que cada país, em âmbito interno, possa desenvolver sua prática específica voltada para as questões de agricultura e de propriedade intelectual. Por isso, existe uma variação considerável em termos de legislação voltada para a regulamentação do direito de propriedade intelectual e da agricultura.

\subsection{Os Organismos Geneticamente Modificados e o Princípio da Precaução}

Revista Brasileira de Políticas Públicas e Internacionais, v.2, n.2, Dezembro/2017, pp. 03-24. 
Não se sabe, ao certo, as consequências que podem surgir a partir dos organismos geneticamente modificados, tanto no âmbito da saúde, como no que diz respeito aos aspectos do meio ambiente. Dessa maneira, por se tratar de uma nova tecnologia e considerando o reduzido conhecimento científico a respeito dos riscos de OGMs, torna-se indispensável que a liberação de plantas transgênicas para plantio e consumo, em larga escala, seja precedida de uma análise criteriosa de risco à saúde humana e do efeito desses produtos e serviços ao meio ambiente, respaldadas em estudos científicos, conforme prevê a legislação vigente.

O avanço da engenharia genética e a introdução no mercado mundial de um novo tipo de alimento "os geneticamente modificados ou transgênicos”, têm gerado muita polêmica. De um lado, a indústria da biotecnologia deposita extrema confiança na segurança da engenharia genética e sua importância para o desenvolvimento econômico e, de outro lado, há uma desconfiança generalizada da sociedade, motivada em parte pela ausência de informação.

Sendo assim, surge a necessidade de estabelecimento de normas adequadas de biossegurança, licenciamento ambiental, mecanismos e instrumentos para monitoramento, no sentido de assegurar o afastamento de danos à saúde humana e animal, assim como danos ao meio ambiente. Por isso, torna-se de substancial importância que cada país estabeleça um padrão de adoção de medidas essenciais de segurança para a produção dos alimentos geneticamente modificados. Essa questão se justifica a partir a ausência de informação sobre as questões relativas aos organismos geneticamente modificados. Por isso, o ordenamento jurídico interno de cada país deve estabelecer padrões normativos essencialmente claros, para que a população possa ter acesso às informações relacionadas com a engenharia genética. Dessa maneira, as informações das leis nacionais devem estar estruturadas a partir de regras e princípios voltados para os direitos humanos e, consequentemente do direito ao desenvolvimento.

Em relação à produção de plantas e sementes geneticamente modificadas, observa-se que existem obstáculos para a reprodução, pois com a modificação genética da semente, surgirão restrições ao uso de elementos do próprio ecossistema pelo oferecimento de sementes melhoradas e mais produtivas que indubitavelmente serão mais utilizadas pelos produtores que visam uma maior

Revista Brasileira de Políticas Públicas e Internacionais, v.2, n.2, Dezembro/2017, pp. 03-24. 
produtividade para concorrer no mercado externo em função da maior possibilidade de obtenção de exportação.

O impacto da utilização dos organismos geneticamente modificados ocorreu no mundo inteiro, pois a falta de conhecimento real sobre as questões em torno dessa nova forma de produção se tornou patente e, em sequência, à medida que as pesquisas eram desenvolvidas, as evidências dos malefícios para a saúde eram evidenciados.

Sendo assim, a insegurança causada pelo uso dos organismos geneticamente modificados passou a ser um problema real, tanto para os países desenvolvidos como para os países em desenvolvimento. O que se observa, na verdade, é o questionamento sobre as consequências do uso desses produtos pelos indivíduos.

No que tange ao meio ambiente, existem estudos revelando as consequências para os seres vivos a partir da utilização de OGMs na agricultura, por exemplo. A exposição de insetos e microorganismos a substâncias tóxicas produzidas pelos vegetais geneticamente modificados podem ocasionar a sua eliminação, provocando sério impacto ambiental.

Além disso, pesquisas citam a possibilidade de algumas culturas transgênicas, quando plantadas sob condições climáticas específicas, apresentarem queda na produtividade em relação à convencional; alteração no metabolismo humano a partir do consumo de certas substâncias transgênicas; oligopolização do mercado de sementes (risco tecnológico); aumento no preço final do produto, a partir da rotulagem de OGMs; dependência e exclusão dos pequenos agricultores, devido ao patenteamento da tecnologia pelas empresas que detêm o tipo de pesquisa (MORAIS 2004).

Os avanços biotecnológicos no campo da agricultura que estão intimamente relacionados com a engenharia genética, com a chegada dos organismos geneticamente modificados, têm sido acompanhados por uma grande polêmica, despertando muitas dúvidas e questionamentos em toda a sociedade, no sentido de qual a real necessidade de se criar OGMs.

Portanto, em face à insegurança gerada pelo uso dos organismos geneticamente modificados, entende-se que a lei que desenvolve culturas resistentes aos herbicidas precisa abrir canais de comunicação e discussão sobre os valores que essa tecnologia pode trazer à agricultura, à sociedade e às estratégias que assegurem o uso responsável e eficiente das culturas resistentes.

Revista Brasileira de Políticas Públicas e Internacionais, v.2, n.2, Dezembro/2017, pp. 03-24. 
Por se tratar de uma nova tecnologia e considerando o reduzido conhecimento científico a respeito dos riscos de OGMs, torna-se indispensável que a liberação de plantas transgênicas para plantio e consumo, em larga escala, seja precedida de uma análise criteriosa de risco à saúde humana e do efeito desses produtos e serviços ao meio ambiente, respaldadas em estudos científicos, conforme prevê a legislação vigente. Assim, normas adequadas de biossegurança, licenciamento ambiental, e mecanismos e instrumentos de monitoramento e rastreabilidade são necessários para assegurar que não haverá danos à saúde humana e animal, bem como danos ao meio ambiente. Também são imprescindíveis estudos de impacto socioeconômicos e culturais, daí a relevância da análise da oportunidade e conveniência que uma nação deve fazer antes da adoção de qualquer produto ou serviço decorrente da transgenia (BRASIL, 2010).

Nessa perspectiva, como forma de auxílio para a tomada de decisões, muita países, acabam por se utilizar do princípio da precaução. E, assim, quando é possível identificar riscos evidentes de prejuízos da biodiversidade e, ainda, para a saúde do individuo, não deve existir resistência na busca por medidas preventivas, mesmo que não existam evidências científicas.

O Princípio da Precaução foi formulado primeiramente pelos gregos e significava ter cuidado e estar ciente. Somente nos anos 70, o Princípio da Precaução foi consolidado na Alemanha em resposta à poluição industrial, ficando conhecido como Vorsorge Prinzip. Passados 20 anos, esse princípio estava disseminado por toda a Europa. Na década de 1990, outra forma de interpretação do Princípio da Precaução foi estabelecida nos Estados Unidos: "É melhor ser grosseiramente certo no tempo devido, tendo em mente as consequências de estar sendo errado do que ser completamente errado muito tarde”. Atualmente, o Princípio da Precaução vem sendo aplicado em todas as áreas da economia, que podem, de alguma maneira, causar danos à saúde humana e ao meio ambiente (NODARI, 2005).

Desta forma, a adoção do Princípio da Precaução constitui uma alternativa concreta a ser adotada diante de tantas incertezas científicas. Desta associação respeitosa e funcional do homem com a natureza, surgem as ações preventivas para proteger a saúde das pessoas e os componentes dos ecossistemas (BRASIL, 2010). Para atender o Princípio da Precaução, a liberação de AGM deve atender às necessidades de informação e de segurança do cidadão consumidor, sendo imprescindível que a avaliação da segurança desse produto aconteça antes da sua introdução no

Revista Brasileira de Políticas Públicas e Internacionais, v.2, n.2, Dezembro/2017, pp. 03-24. 
mercado de consumo (BARROS, 2008). Portanto, a responsabilidade sobre as questões de biossegurança é de cada sistema jurídico.

\section{Uso dos Transgênicos, Sistema Jurídico Internacional e o Princípio da Precaução}

Como elucidado, os transgênicos causaram um impacto significativo no âmbito internacional, no sentido da aceitação por partes dos países. Nesse sentido, no ano de 2000, o sistema jurídico internacional começa a se movimentar no sentido de regulamentar as questões dos organismos geneticamente modificados, no sentido de equilibrar os interesses entre as partes envolvidas na polêmica.

Nessa perspectiva, surge o protocolo internacional de biossegurança ou protocolo internacional de Cartagena com o objetivo de contribuir para a garantia de um nível adequado de proteção à transferência, manipulação e utilização segura dos organismos vivos modificados resultantes da biotecnologia moderna, que possam ter efeitos adversos na conservação e na utilização sustentável da diversidade biológica, levando-se em conta os riscos para a saúde humana.

O Protocolo de Cartagena sobre Biossegurança (PCB) é um tratado ambiental que faz parte da Convenção sobre Diversidade Biológica (CDB). O PCB foi criado para tratar dos produtos transgênicos no âmbito da CDB. Esse protocolo internacional resultou da Conferência das Partes da CDB, realizada em 17 de novembro de 1995, com o objetivo de criar segurança relativa a produtos da biotecnologia, principalmente "focado no movimento transfronteiriço de quaisquer transgênicos, resultantes da biotecnologia, e que possam ter efeitos adversos sobre a conversação e utilização sustentável da diversidade biológica” (FILHO, 2014).

Torna-se importante observar ainda que, no protocolo internacional de Cartagena, existe a menção ao princípio da precaução, de forma que se evidenciam os elementos essenciais para utilização pelos ordenamentos jurídicos quando das questões que podem afetar a biodiversidade.

Importante discussão e consequente proteção trazida por este diploma internacional foi a questão da soberania dos países sobre os seus recursos biológicos, uma vez que o pensamento que prevalecia na época era que a biodiversidade era uma herança comum da humanidade, permitindo ao país que descobriu aquele recurso, explorar sem contrapartida para o país de origem.

Revista Brasileira de Políticas Públicas e Internacionais, v.2, n.2, Dezembro/2017, pp. 03-24. 
O protocolo determina, ainda, que o acesso deverá ser de comum acordo, consentido previamente, bem como os benefícios deverão ser distribuídos de forma justa e igualitária, aduzidos de sua utilização comercial e científica. Aqui, destaca-se que a biodiversidade tem relação direta com as biotecnologias, uma vez que é matéria-prima imprescindível para o desenvolvimento da atividade agrária e da economia.

Por outro lado, devido aos crescentes problemas ambientais em todo o planeta, " $a$ ONU encampou no universo de suas atividades e atribuições a discussão sobre a preservação ambiental e sua conciliação com a necessidade das atividades econômicas da sociedade humana” (MAGALHÃES, p. 173, 2011).

Assim, com vistas a sanar os conflitos de propriedade intelectual, a Organização das Nações Unidas - ONU criou, através dos seus conselhos, a Conferência das Nações Unidas sobre Comércio e Desenvolvimento - CNDUCD, com a previsão para ocorrer a cada 4 anos, e o Comitê de Direitos Econômicos, Sociais e Culturais. Este último criado em 1985 pela Resolução 1985/17.

Contudo, apesar dos esforços para a proteção da biodiversidade e da propriedade intelectual na modalidade propriedade industrial e na modalidade direitos autorais, observa-se que as regras ainda são esparsas e, em muitas delas, há o conflito com a própria CDB. Este fato é tão verdadeiro que, constantemente, vislumbra-se violações a estes direitos através da biopirataria ferindo gravemente a diversidade do patrimônio genético nacional e, em consequência, a soberania.

\section{Biossegurança e o Direito ao Desenvolvimento}

Há pouca dúvida de que os avanços na biotecnologia podem afetar o dia a dia da sociedade, especialmente, quando surge a preocupação de que, para os países em desenvolvimento, haverá uma restrição patente no acesso à tecnologia desenvolvida no âmbito da biodiversidade. Sendo assim, a biossegurança surge como instrumento essencial para garantir a manutenção equilibrada do sistema de produção agrícola.

Nesse sentido, biossegurança refere-se ao processo de proteção para a melhoria das culturas, conservação da biodiversidade, redução dos riscos de biopirataria, combate às pragas e doenças, com o intuito exclusivo de garantia do bem-estar da humanidade. Ainda mais, a biossegurança deve

Revista Brasileira de Políticas Públicas e Internacionais, v.2, n.2, Dezembro/2017, pp. 03-24. 
ser compreendida a partir de uma abordagem que integra elementos estratégicos de: segurança alimentar, vida animal, vegetal e de saúde, e ainda, os riscos ambientais.

Por isso, o objetivo da biossegurança é identificar, avaliar e responder adequadamente a todas as pragas e doenças que representem uma ameaça significativa para a agricultura, à silvicultura, à horticultura, à pesca, à biodiversidade nativa e à saúde humana. No âmbito internacional, a biossegurança está prevista de maneira expressa em apenas quatro acordos internacionais. O termo de biossegurança surge a partir de estudos desenvolvidos nos seguintes dispositivos jurídicos internacionais, nomeadamente, acordo da organização mundial do comércio sobre a aplicação de medidas sanitárias e fitossanitárias, convenção sobre a diversidade biológica (CBD) e o protocolo de Cartagena sobre biossegurança, a comissão codex alimentarius, a organização mundial sobre saúde animal e a convenção fitossanitária internacional.

Sendo assim, quando se analisam os elementos que envolvem as questões sobre biossegurança, observa-se uma aproximação considerável dos elementos previstos da Declaração de Direito ao desenvolvimento e, ainda, na Declaração Universal de Direitos do Homem, especificamente, quando se analisa a segurança alimentar que é o acesso à alimentação de qualidade, o que incorre na garantia do direito à saúde e à educação, ou seja, o direito ao desenvolvimento atravessa elementos essenciais à condição humana. Por isso, as garantias normativas previstas no âmbito internacional precisam ser efetivadas. Os critérios para efetivação dos direitos humanos através da segurança alimentar são essenciais e, por isso, qualquer atuação, no sentido de violar os direitos humanos no âmbito da qualidade de vida através da segurança alimentar, deve ser afastada.

Não se pode falar em segurança alimentar, ou simplesmente em direito à alimentação, se os países não estabelecerem políticas públicas adequadas para o plano de agricultura alimentar, que possam abarcar todos os indivíduos de maneira adequada. O que deve ser levado em consideração é que a segurança alimentar deve ser a partir de uma alimentação de qualidade e não qualquer questão sobre alimentação.

Partindo dos elementos jurídicos internacionais estabelecidos no âmbito da biodiversidade, observa-se que os objetivos que se desejam alcançar são referentes à conservação da biodiversidade,

Revista Brasileira de Políticas Públicas e Internacionais, v.2, n.2, Dezembro/2017, pp. 03-24. 
ao uso sustentável dos recursos genéticos e, ainda, à partilha justa e equitativa dos benefícios decorrentes da utilização dos recursos.

Portanto, os elementos indicados nos acordos internacionais, como é o caso do acordo TRIPS/OMC são medidas que visualizam a conservação e o uso sustentável dos componentes na biodiversidade. Nesse contexto, o acordo TRIPS leva em consideração a transferência de tecnologia, gestão de biotecnologia e distribuição de benefícios e mecanismos financeiros. O texto estabelecido no acordo TRIPS, especificamente no artigo $6^{\circ}$, analisa o compromisso das partes contratantes em motivar o desenvolvimento de estratégias nacionais para a conservação e distribuição de benefícios para a biodiversidade.

Ao ressaltar essa importância, observa-se a integração com o texto estabelecido na Declaração de direito ao desenvolvimento no artigo 8, ao dispor que:

Os Estados devem pôr em prática, a nível nacional, todas as medidas necessárias para a realização do direito ao desenvolvimento e deverão assegurar, nomeadamente, a igualdade de oportunidades para todos no acesso aos recursos básicos, à educação, aos serviços de saúde, à alimentação, à habitação, ao emprego e a uma justa distribuição dos rendimentos. Devem ser adoptadas medidas eficazes para garantir que as mulheres desempenhem um papel activo no processo de desenvolvimento. Devem ser levadas a cabo reformas econômicas e sociais adequadas a fim de erradicar todas as injustiças sociais. Os Estados devem encorajar a participação popular em todas as áreas enquanto factor importante para o desenvolvimento e para a plena realização de todos os direitos humanos (ONU 1986).

Apesar de ser um dispositivo um pouco amplo, não se pode olvidar dos elementos de respeito aos direitos humanos através das políticas nacionais para motivação do crescimento da qualidade de vida. Aliado a essa situação, o acordo TRIPS também enaltece a importância da realização das políticas nacionais de motivação do direito ao desenvolvimento. A questão que se discute, portanto, seria a identificação de quais medidas poderiam ser consideradas eficazes para a proteção da biodiversidade.

Sabendo-se, contudo, que o termo biodiversidade é bastante amplo, propõe-se, portanto, uma adequação voltada para os elementos que visualizem o bem-estar da população em todos os sentidos. Sendo assim, na perspectiva da biossegurança com o uso dos organismos geneticamente

Revista Brasileira de Políticas Públicas e Internacionais, v.2, n.2, Dezembro/2017, pp. 03-24. 
modificados, os países devem estabelecer políticas nacionais, no sentido de afastar qualquer prática por parte das empresas que possa se tornar prejudicial para a sociedade civil.

4.1. A lei de biossegurança e os sistemas jurídicos nacionais dos BRICS a partir de um mundo socialmente desenvolvido

Como elucidado anteriormente, cada país possui seu sistema jurídico próprio no sentido de estabelecer regras específicas para tratamento da biossegurança. Portanto, deve-se evidenciar que, para questões de biossegurança, não haverá uma padronização de regras entre os sistemas jurídicos nacionais.

Entretanto, os países, dentro das suas perspectivas, devem seguir o padrão mínimo de estruturação das regras sobre biossegurança. Importante ressaltar que a falta de padronização, no âmbito internacional, decorre da falta de harmonização normativa em virtude dos elementos evidenciados pela soberania. Nessa perspectiva, analisam-se os sistemas jurídicos dos países, nomeadamente os que compõem os BRICS, que se propõem a desenvolver o estudo comparativo entre Estados Unidos e União Europeia.

Em se tratando de União Europeia, observam-se os elementos dispostos na legislação do bloco econômico ao preceituar um tratamento adequado destinado à proteção à saúde e, ainda, à preservação do meio ambiente, perante o mercado da biotecnologia que vem se desenvolvendo abruptamente. Sendo assim, o complexo jurídico da União Europeia é composto por alguns regulamentos e diretivas que abordam elementos relativos à colocação de produtos transgênicos no mercado.

Neste contexto, foi criada a autoridade europeia para a segurança dos alimentos, que estabeleceu diretrizes gerais que regem a legislação alimentar no bloco econômico europeu. As atividades que devem ser desenvolvidas pela autoridade europeia para a segurança dos alimentos é o aconselhamento sobre os riscos existentes e emergentes que estão diretamente relacionados com os alimentos.

Seria, na verdade, a aplicação do princípio da precaução no âmbito das diretivas e regulamentos estabelecidos pela autoridade europeia. Portanto, as atividades desenvolvidas no âmbito do referido órgão dizem respeito à necessidade de afastamento dos riscos observados na

Revista Brasileira de Políticas Públicas e Internacionais, v.2, n.2, Dezembro/2017, pp. 03-24. 
cadeia alimentar. Nesse sentido, a autoridade europeia busca o estabelecimento de procedimentos para a autorização e supervisão dos gêneros alimentícios e alimentos para animais que sejam geneticamente modificados, no sentido de assegurar a segurança alimentar. Uma das medidas mais marcantes realizadas pela autoridade europeia é a exigência das informações através dos rótulos dos alimentos (o direito do consumidor de ser informado) acerca do alimento que consome.

O padrão europeu no que diz respeito à segurança dos alimentos transgênicos é bastante rigoroso, diferentemente da prática de outros países, como é o caso dos EUA e dos países que compõem os BRICS. O padrão rigoroso por parte da União Europeia acerca dos alimentos transgênicos demonstra a preocupação com a saúde e, ainda, com a preservação ambiental. Observa-se, portanto, que os países produtores de transgênicos estariam cobrando uma posição mais liberal da União Europeia, no sentido de firmar acordos para auxiliar o desenvolvimento do comércio internacional.

A liberação dos transgênicos na UE torna-se mais rigorosa, pois somente será autorizada a circulação desses produtos após se certificarem Se certificarem de quê? por meio de um processo de avaliação, o qual será autorizado e rotulado com a especificação correta, respeitando o percentual na composição que é de 1\% (FROTA, 2007).

O Brasil ocupa o segundo lugar em área de OGMs plantada, perdendo apenas para os EUA, e tem emergido como um líder global na área de OGM. Pelo terceiro ano consecutivo, o Brasil se apresenta como a força motriz do crescimento global, aumentando a sua área mais do que qualquer outro país no mundo. Em 2011, essa área cresceu 4,9 milhões de hectares, o que equivale a um incremento de $20 \%$ ao ano. O motivo desse grande crescimento refere-se ao fato do rápido sistema de aprovação desses cultivares, o que permitiu ao Brasil aprovar oito eventos em 2010 e, até outubro de 2011, mais seis eventos (JAMES, 2011).

De maneira um pouco semelhante ao padrão europeu, o Brasil também trabalha com o cultivo dos organismos geneticamente modificados, seguindo especificamente a edição da Lei 11346/2006. O intuito é garantir o direito humano à alimentação adequada, ao estabelecer, no artigo $2^{\circ}$, como direito fundamental, uma alimentação adequada inerente à dignidade da pessoa humana e indispensável à realização dos direitos consagrados na Constituição Federal.

Revista Brasileira de Políticas Públicas e Internacionais, v.2, n.2, Dezembro/2017, pp. 03-24. 
O princípio da precaução foi introduzido às normativas brasileiras com a formulação da Constituição Federal de 1988, que apresentou as primeiras normas voltadas especificamente para a defesa do meio ambiente. Essa abordagem transmite à sociedade e ao Poder Público o dever de defender e preservar o meio ambiente de forma a evitar que prevaleça apenas o intuito corretivo, que também existe na forma de sanções e punições para os causadores dos danos. Com isso, são introduzidos os preceitos da legislação de OGM e o conceito de estudo prévio de impacto ambiental (MORICONI et al. , 2014).

Portanto, analisando ambos os dispositivos legislativos, observa-se que o sistema governamental brasileiro deverá introduzir políticas públicas e ações que se façam necessárias para promover e garantir a segurança alimentar e nutricional à população. Tais políticas públicas evidenciam os elementos relacionados com o princípio da precaução.

Por isso, o sistema de biossegurança do Brasil passa pela questão da rotulagem dos produtos, pois parte-se do pressuposto de que se a população tem acesso às informações adequadas apontadas nos produtos, poderá haver a devida instrução dos consumidores e, consequentemente, o afastamento de problemas que podem ser prejudiciais à população e ao meio ambiente.

Assim, o primeiro impacto das normas internacionais sobre a política e a legislação brasileira foi derivado do regime de proteção ao consumidor como resultado da convergência entre os regimes ambiental e comercial. Se essa tendência se confirmar, o direito do consumidor será fortalecido nos próximos anos. Isso se deve ao fato de que o Brasil está mudando de uma posição anti-OGM para uma posição favorável ao contexto dos OGMs sob certas condições legais. Consequentemente, a posição internacional do país em relação aos OGMs também tem mudado rapidamente (BARROS, 2008).

A legislação sobre a utilização de técnicas para a elaboração de organismos geneticamente modificados é bastante flexível, pois passa a considerar os alimentos transgênicos como substancialmente equivalentes aos alimentos tradicionais, excluindo a obrigatoriedade de submissão dos produtos aos testes da FDA e da agência de proteção ambiental. Importante ressaltar que, o posicionamento dos Estados Unidos é bastante diferente do que é preceituado pelo ordenamento jurídico europeu (RODRIGUES, 2002), uma vez que a rotulagem nos produtos geneticamente modificados não é algo obrigatória, ficando a critério de cada empresa.

Revista Brasileira de Políticas Públicas e Internacionais, v.2, n.2, Dezembro/2017, pp. 03-24. 
Dessa maneira, observa-se a restrição das informações essenciais por parte do consumidor nas embalagens dos produtos, portanto, não ficarão evidenciados os riscos que os consumidores estarão sujeitos, já que não terão acesso às informações nutricionais dos produtos.

A falta de regulamentação na rotulagem dos produtos acaba por gerar qualquer lesão à saúde do consumidor. E, diante desse contexto, no que diz respeito aos direitos humanos e ao direito ao desenvolvimento, observa-se que o Brasil e a União Europeia estão em situação de destaque.

O mercado de transgênicos na China é bastante promissor, de forma que conseguiu, com a união de todos os países em desenvolvimento, ultrapassar o mercado de produção dos países desenvolvidos. A China é um dos maiores produtores de algodão GM no mundo e, como tal, é um dos maiores importadores de culturas biotecnológicas do mundo.

Entretanto, o sistema de produção das principais culturas de biotecnologia no país ainda não foi desenvolvido, em virtude do receio da população sobre a segurança alimentar. No ano de 2015, a China lançou uma proposta de reforma jurídica no regulamento sobre gestão de biossegurança de 2004.

E, apesar de ter um sistema de agricultura transgênica em franca expansão, a China aplica em seu sistema normativo, a necessidade de regulamentação das questões acerca da rotulagem dos produtos. Dessa maneira, da revisão da lei de segurança alimentar da China incorpora disposições sobre rotulagem de produtos de biotecnologia, situação que iria criar obstáculos para a entrada no mercado de produtos não rotulados ou com rótulos errados.

A China aperfeiçoou o sistema de propaganda enganosa nos produtos transgênicos e, nessa perspectiva, observa-se, portanto, que o sistema jurídico Chinês incorpora também o princípio da precaução no que tange aos produtos transgênicos. Isso acontece não no que diz respeito à proibição de produção de transgênicos em seu território, mas apenas nas questões relacionadas com a rotulagem dos produtos.

A estratégia jurídico-política da Rússia é bastante semelhante ao que é apresentado pela União Europeia e pelo Japão, se afastando, portanto, das políticas praticadas pelos Estados Unidos, China e Brasil. O quadro jurídico russo regula a segurança dos produtos transgênicos, e o controle sobre a sua circulação no mercado consiste principalmente de várias leis federais e resoluções governamentais que regulam a política de biotecnologia agrícola.

Revista Brasileira de Políticas Públicas e Internacionais, v.2, n.2, Dezembro/2017, pp. 03-24. 
O quadro jurídico russo sobre a segurança dos produtos transgênicos (controle da circulação e da produção) é composto por várias leis federais e resoluções governamentais. Ainda na mesma perspectiva, o sistema jurídico russo observou, em 2015, a intenção de implementar uma política destinada a proibir a utilização de sementes geneticamente modificadas, plantas e animais, por qualquer razão, exceto em casos quando feito para fins de pesquisa científica.

A Rússia estabeleceu acordos de comércio com a Bielorrússia e com o Cazaquistão no sentido de harmonizar as tarifas comerciais. O Regulamento sobre produtos alimentares é projetado para estabelecer requisitos uniformes para a rotulagem de produtos no sentido de garantir a livre circulação dos produtos alimentares introduzidos no território dos Estados membros. O referido acordo abrange normas e requisitos para grãos e sementes produzidos e comercializados no território dos países signatários do acordo.

Sendo assim, a responsabilização por violação dos acordos estabelecidos no sistema jurídico russo é bastante interessante, pois em termos pecuniários, os valores são tratados de maneira irrelevante, apesar de as questões jurídicas serem bastante rigorosas. Assim, a venda de produtos com ausência de informações essenciais para a introdução no mercado é passível de responsabilização, nos termos de suspensão de comercialização e ainda na imputação de multa pecuniária.

Diante do que foi exposto, o sistema jurídico russo atravessa um processo de adequadação no que diz respeito ao sistema da agricultura geneticamente modificada e, apesar de existir a possibilidade de produção e comercialização no mercado interno, o país se preocupa com a segurança alimentar e, em virtude destas questões, o princípio da precaução evidenciado no protocolo de Cartagena é, de fato, levado em consideração.

No caso do sistema jurídico indiano, existe a previsão legal tendo em vista os riscos potenciais para a saúde humana e para o meio ambiente, quando do uso indiscriminado. O sistema regulatório de biossegurança na Índia evoluiu em resposta aos avanços observados nas ciências biológicas e nas preocupações dos cidadãos indianos, cientistas e agências do governo em relação aos produtos de biotecnologia que estavam sendo produzidos através da nova biologia.

O objetivo do sistema regulatório indiano é assegurar que os cultivos transgênicos não representam grande risco para a segurança alimentar, segurança ambiental e produção agrícola, e

Revista Brasileira de Políticas Públicas e Internacionais, v.2, n.2, Dezembro/2017, pp. 03-24. 
que não haja impactos econômicos negativos sobre os agricultores. Este último é um objetivo que muitos países desenvolvidos não incluem em seus sistemas reguladores. Entretanto, mesmo sendo possível identificar uma legislação de combate ao uso de alimentos que gerem riscos para a segurança alimentar, ambiental e produção agrícola, existem casos que ocorrem na Índia que são considerados, especialmente, violações de Direitos Humanos.

O primeiro caso de cultivo de transgênico na Índia ocorreu, no ano de 2002, com a Monsanto. Tratava-se da inserção de cultivares híbridos em algodões pertencentes à empresa indiana Mahyco (PRAY, 2005). A Monsanto é uma empresa multinacional, de origem americana, cujo trabalho é voltado para a agricultura e a biotecnologia.

A empresa também é líder no desenvolvimento de sementes geneticamente modificadas, abarcando um mercado monopolizador, pois atinge grande parcela da produção de sementes no mundo inteiro, já que várias filiais da empresa estão espalhadas pelo mundo inteiro.

Sendo assim, em decorrência desse monopólio, a produção mundial de alimentos tem atravessado um forte período de turbulência, pois os agricultores estão constatando a dependência na produção e, ainda, de certa forma, o empobrecimento, em virtude dos contratos que são assinados com as empresas de transgênicos, gerando a proibição do plantio das sementes que são produzidas nas colheitas, obrigando os agricultores a comprarem novas sementes transgênicas a cada novo plantio.

O fato de as sementes geneticamente modificadas possuírem a proteção patentária, gera a necessidade do manejo exclusivo tanto das sementes como da produção, pois é um processo que requer insumos exclusivos (produtos químicos que a própria empresa de sementes fabrica).

Entretanto, o monopólio da Monsanto tem gerado lides complexas no mundo inteiro. Na Índia, a Monsanto ocupa quase 100\% do mercado de sementes de algodão, situação que obriga os agricultores a comprarem as sementes transgênicas e, consequentemente, todos os produtos químicos. Como os frutos das sementes não podem ser reproduzidos, os agricultores acabam tendo que adquirir novas sementes e, como agravante, as empresas praticam preços altíssimos na venda de tais sementes. E, ainda, as questões ambientais na Índia acabam por prejudicar a reprodução das sementes, pois a perda nas plantações passou a ser significativa e, consequentemente, acabou por gerar o endividamento dos agricultores indianos.

Revista Brasileira de Políticas Públicas e Internacionais, v.2, n.2, Dezembro/2017, pp. 03-24. 
Ademais, observou-se que as sementes produzidas pela Monsanto apresentavam um alto grau de contaminação, situação que gerava riscos para os produtores e consumidores. Diante do exposto, observa-se que na legislação indiana, apesar de conter elementos acerca do princípio da precaução, que deveria combater a introdução no mercado de sementes intoxicadas que podem prejudicar a saúde pública e, ainda, a manutenção do meio ambiente, existe o monopólio da semente por parte da Monsanto.

As consequências do uso de sementes da Monsanto são as mais variadas, visto incluir desde questões da saúde pública como das condições financeiras dos agricultores. Nesse sentido, os agricultores motivados por questões financeiras e apoiados pelo próprio governo indiano envidam esforços para sedimentar a agricultura orgânica na Índia. Os resultados estão sendo bastante positivos, de forma que a Monsanto tem perdido parcela do mercado de sementes para os agricultores na Índia.

A realidade da África do Sul é bastante complexa, quando é comparada às questões identificadas nos demais países que compõem os BRICS. A situação decorre justamente do problema da fome que acomete grande parte da população. E, dessa maneira, os organismos internacionais, em especial a Organização das Nações Unidas, estabelecem políticas setoriais de combate a fome não apenas na África do Sul, mas nas demais regiões da África.

Nessa perspectiva, a África do Sul identifica como solução viável para o combate a fome, a produção dos organismos geneticamente modificados. É importante destacar que quase 90\% do milho produzido na África do Sul são geneticamente modificados. Essa situação decorre justamente das dificuldades climáticas e econômicas que são enfrentadas pela África do Sul.

A legislação nacional da África do sul é um pouquinho ampla no que diz respeito aos organismos geneticamente modificados, mesmo assim o princípio da precaução é evidentemente identificado. No entanto, as condições sociais África do Sul acaba por relaxar em alguns aspectos relativos à rotulagem dos produtos alimentícios. Ver o conteúdo depois da alteração.

Essa situação pode prejudicar a saúde da população e, consequentemente, a efetivação do direito ao desenvolvimento. O relaxamento das regras de importação sobre os organismos geneticamente modificados tem o objetivo de evitar uma potencial crise alimentar em meio às dificuldades sociais e econômicas vivenciadas pela África do Sul.

Revista Brasileira de Políticas Públicas e Internacionais, v.2, n.2, Dezembro/2017, pp. 03-24. 
Diante do que se discutiu, observou-se tanto nos países desenvolvidos como nos países em desenvolvimento, certa preocupação no que diz respeito ao patenteamento dos organismos geneticamente modificados, em virtude dos impactos econômico, social e ambiental e ético. E, apesar de ser uma necessidade real a questão da alimentação, os países temem os problemas que podem surgir com a segurança alimentar. Dever-se-á, portanto, buscar um equilíbrio dos elementos observados entre as patentes que envolvem a biodiversidade e o interesse da população, com o intuito de atingir eficazmente o direito ao desenvolvimento.

\section{Conclusão}

Não se pode olvidar que o sistema agrícola mundial mudou com o passar dos anos, em virtude das adversidades que surgiram nas várias regiões do mundo, acarretando um aumento significativo no preço dos alimentos e, consequentemente, interferindo diretamente na rotina da população. Nesse sentido, pode-se observar o fortalecimento dos direitos de propriedade intelectual a partir do advento de convenções internacionais, bem como uma alta influência do sistema de propriedade intelectual nas atividades desempenhadas pelas empresas transnacionais do setor agrícola.

O intenso desenvolvimento industrial e a expansão do comércio nos países desenvolvidos fizeram surgir a necessidade de proteger o meio ambiente em sua integralidade. $\mathrm{O}$ avanço da engenharia genética e a introdução no mercado mundial de um novo tipo de alimento "os geneticamente modificados ou transgênicos” têm gerado muita polêmica. De um lado, a indústria da biotecnologia deposita extrema confiança na segurança da engenharia genética e na sua importância para o desenvolvimento econômico e, de outro lado, há uma desconfiança generalizada da sociedade, motivada em parte pela ausência de informação.

Como elucidado acima, os transgênicos causaram um impacto significativo no âmbito internacional no sentido da aceitação por parte dos países, fazendo com que o sistema jurídico começasse a se movimentar no sentido de regulamentar as questões dos organismos geneticamente modificados a fim de equilibrar os interesses entre as partes envolvidas na polêmica.

Portanto, verificou-se a forte insegurança gerada pelo uso dos organismos geneticamente modificados, uma vez que se entende que a lei que desenvolve culturas resistentes aos herbicidas

Revista Brasileira de Políticas Públicas e Internacionais, v.2, n.2, Dezembro/2017, pp. 03-24. 
precisa abrir canais de comunicação e discussão sobre os valores que essa tecnologia pode trazer à agricultura, à sociedade e às estratégias que assegurem o uso responsável e eficiente das culturas resistentes.

Constata-se a premente necessidade de estabelecimento de normas adequadas de biossegurança, licenciamento ambiental, mecanismos e instrumentos para monitoramento no sentido de assegurar o afastamento de danos à saúde humana e animal, bem como danos ao meio ambiente. É, portanto, de substancial importância que cada país estabeleça um padrão de adoção de medidas essenciais de segurança para a produção dos alimentos geneticamente modificados.

Há que se ressaltar, ainda, que as informações das leis nacionais devem estar estruturadas a partir de regras e princípios voltados para os direitos humanos e, consequentemente do direito ao desenvolvimento.

Desta forma, a adoção do Princípio da Precaução constitui uma alternativa concreta a ser adotada diante de tantas incertezas científicas. Para que se atenda ao citado princípio, viu-se que a liberação de AGM deve atender às necessidades de informação e segurança do cidadão consumidor, sendo imprescindível que a avaliação da segurança desse produto aconteça antes da sua introdução no mercado de consumo. Portanto, a responsabilidade sobre as questões de biossegurança é de responsabilidade de cada sistema jurídico.

Sabendo-se, contudo, que o termo biodiversidade é bastante amplo, propõe-se, portanto, uma adequação voltada para os elementos que visualizem o bem-estar da população em todos os sentidos, efetivando-se de maneira mediata a própria cidadania. Sendo assim, na perspectiva da biossegurança com o uso dos organismos geneticamente modificados, os países devem estabelecer políticas nacionais no sentido de afastar qualquer prática por parte das empresas, que possa se tornar prejudicial para a sociedade civil.

Constatou-se, tanto nos países desenvolvidos como nos países em desenvolvimento, certa preocupação no que diz respeito ao patenteamento dos organismos geneticamente modificados, em virtude dos impactos econômico, social e ambiental e ético. E, apesar de ser uma necessidade real a questão da alimentação, os países temem os problemas que podem surgir com a segurança alimentar. Dever-se-á, portanto, buscar um equilíbrio dos elementos observados entre as patentes

Revista Brasileira de Políticas Públicas e Internacionais, v.2, n.2, Dezembro/2017, pp. 03-24. 
que envolvem a biodiversidade e o interesse da população, com o intuito de atingir eficazmente o direito ao desenvolvimento.

Diante do que foi discutido neste artigo, observa-se que o reforço da proteção do direito de propriedade intelectual pode tornar mais lucrativo o investimento da indústria de biotecnologia, de modo que é possível argumentar que o acordo TRIPS promove a adoção dos organismos geneticamente modificados no sistema alimentar.

Por fim, ressalta-se a relevância de se continuar a investigação iniciada sobre o tema em comento, haja vista a sua indiscutível importância para a efetivação da cidadania, através dos atores globais, tanto nacionais, quanto internacionais, através da viabilização da concretude do próprio direito ao desenvolvimento.

\section{Referências}

Afori, Orit Fischman (2004). Human Rights and Copyright: The Introduction of Natural Law Considerations into American Copyright Law. Fordham Intellectual Property, Media and Entertainment Law Journal. Volume 14, Issue 22004 Article 4 Volume XIV Book 2. P. 524.

Anderson-Sprecher, Andrew; Jie, Ma (2015). China - Peoples Republic of Agricultural Biotechnology Annual China Considering Major Revisions to Biotechnology Regulations. Disponível em: https://gain.fas.usda.gov/Recent\%20GAIN\%20Publications/Agricultural\%20Biotechnology\%20An nual_Beijing_China\%20-\%20Peoples\%20Republic\%20of_12-21-2015.pdf. Acesso em: 11 Dez. 2017.

Barros NEF, Oliveira EMM, Marin VA (2008). Aplicabilidade da metodologia de reação de polimerase em cadeia em tempo real na determinação do percentual de organismos geneticamente modificados em alimentos. Rev. Nutri. 2008; 21(1):85-92.

Filho, Romero Gonçalves Maia (2014). Conflito entre as determinações da convenção sobreadiversidade biológica e as regras do acordo TRIPS.In:http://www.funag.gov.br/biblioteca/dmdocuments/Conflito_entre_as_determinacoes_da_ convencao_sobre_diversidade.pdf. 2014. Acesso em 10 de Janeiro 2017.

Magalhães, Vladimir Garcia (2011). Propriedade intelectual: biotecnologia e biodiversidade. São Paulo: Editora Fiuza, 2011.

Minahim, Maria Auxiliadora (2005). Direito Penal e biotecnologia. São Paulo: Editora Revista dos Tribunais.

Revista Brasileira de Políticas Públicas e Internacionais, v.2, n.2, Dezembro/2017, pp. 03-24. 
Ming, Hu; Jiao, Feng (2014). Legal Protection of China's Biotechnology Patents. Biotechnology law report. June2014. Vol 33. N.3; 103-107

Morais, Roberta Jardim de (2004). Segurança e rotulagem de alimentos geneticamente modificados - seragem: uma abordagem do direito econômico. 1.ed. Rio de Janeiro: Forense, 2004.

Moriconi, Patrícia Rossi; Tonietti, Paloma de Oliveira; Moreno, Luisa Zanolli; Matté, Glavur Rogério (2014). Regulação de organismos geneticamente modificados de uso agrícola no brasil e sua relação com os modelos normativos europeu e estadunidense. $R$. Dir. sanit., São Paulo, v. 14, n. 3, p. 112-131, nov. 2013/ fev. 2014.

Organização das Nações Unidas (1986). Texto da Declaração de Direito ao Desenvolvimento. ONU : Nova Iorque.

Pray, Carl E.; Bengali, Prajakta (2005). The cost of biosafety regulations: the Indian experience. Quarterly Journal of International Agriculture 44, No. 3.

Rodrigues, Maria Rafaela Junqueira Bruno (2002). Biodireito: alimentos transgênicos. 1. ed. São Paulo: Lemos e Cruz.

Revista Brasileira de Políticas Públicas e Internacionais, v.2, n.2, Dezembro/2017, pp. 03-24. 